\title{
Peningkatan Stabilitas Lereng Lapisan Tanah Liat Penahan Lindi TPA dengan Penambahan Limbah Bangunan
}

\author{
Mochamad Arief Budihardjo $\left.{ }^{1, *}\right)$ \\ 1) Departemen TeknikLingkungan,Fakultas Teknik, Universitas Diponegoro, JI. Prof. Soedarto, \\ $\mathrm{SH}$, Kampus Undip Tembalang, Semarang, Indonesia 50275 \\ e-mail:m.budihardjo@ft.undip.ac.id
}

\begin{abstract}
Abstrak
Liner merupakan komponen terpenting dalam fasilitas tempat pengolahan akhir (TPA) sampah untuk mencegah lindi mencemari tanah. Bahan yang sering digunakan sebagai liner adalah tanah lempung yang memiliki permeabilitas rendah. Salah satu tanah lempung alami yang dapat digunakan sebagai liner TPA adalah bentonit. Bentonit memiliki permeabilitas yang sangat rendah, namun stabilitas gesernya tidak begitu kuat sehingga berpotensi mengalami keruntuhan apabila digunakan di daerah lereng.Di sisi lain, limbah bangunan yang berupa pecahan batu bata, campuran pasir dan semen, serta beton memiliki kuat geser yang tinggi dan berpotensi sebagai campuran bentonit. Pada penelitian ini, limbah bangunan sebanyak 5\%, $10 \%$, dan $15 \%$ ditambahkan pada bentonit untuk meningkatkan kekuatan geser bentonit sehingga didapatkan campuran bahan semi kedap dengan stabilitas yang lebih tinggi dan permeabilitas rendah. Hasil uji stabilitas geser yang dilakukan pada tegangan normal $50 \mathrm{kPa}$, $100 \mathrm{kPa}$, dan $200 \mathrm{kPa}$ menunjukkan bahwa semakin meningkatnya konsentrasi campuran bahan bangunan, maka semakin meningkat pula nilai tegangan geser yang dihasilkan.
\end{abstract}

Kata kunci: bentonit; limbah bangunan; kuat geser

\begin{abstract}
Liner is an important component in landfill to prevent leachate polluting the soil. Liner is usually made of clay which has very low permeability. One of the natural clays used as a landfill liner is bentonite. Bentonite has a low hydraulic conductivity value that suitable as landill liner, but limited shear strength that potential to collapse in the slope area. On the other hand, construction waste like crushed brick, mixture of sand \& cement, and concrete have higher shear strength and has potential to be used as bentonite mixture. In this study, construction waste with a composition of $5 \%, 10 \%$ and $15 \%$ was added to the bentonite to obtain a mixture of materials with higher stability and low permeability. Shear stress test results which are carried out at normal stresses of $50 \mathrm{kPa}, 100 \mathrm{kPa}$, and $200 \mathrm{kPa}$ indicate that the increasing concentration of the mixture of construction materials make the shear stress value increased too.
\end{abstract}

Keywords: bentonite; construction waste; shear strength

Pendahuluan

Pertumbuhan penduduk dan ekonomi yang cepat membuat permasalahan persampahan menjadi salah satu permasalahan utama dalam lingkungan perkotaan. Pengelolaan persampahan di negara-negara berkembang biasanya masih menggunakan cara tradisional, yaitu penimbunan langsung di tempat pengolahan akhir (TPA) (Manaf, Samah dan Zukki, 2005). Namun, konsep penanganan sampah di TPA juga dapat menimbulkan permasalahan bagi lingkungan karena selama proses dekomposisi bahan organik di TPA, gas $\left(\mathrm{CH}_{4}\right.$, $\mathrm{CO}_{2}, \mathrm{H}_{2} \mathrm{~S}$ ) dan lindi akan dihasilkan yang berpotensi mencemari lingkungan (Zhang, Tan dan Gersberg, 2010). Lindi yang merupakan hasil dari perkolasi air hujan melalui sampah dapat menyebabkan pencemaran lingkungan karena mengandung zat organik, logam berat, garam organik dan garam inorganik(Renou et al., 2008). Sehingga diperlukan pemasangan lapisan semi kedap (liner) di bagian bawah TPA untuk mencegah masuknya lindi ke tanah dan 
mencemari lingkungan sekitar TPA(Falamaki et al., 2018).

Liner merupakan lapisan semi kedap yang berfungsi untuk menahan terjadinya difusi polutan dan menahan masuknya lindi dalam tanah (He et al., 2015). Lapisan kedap air TPA biasanya terdiri dari bahan-bahan yang memiliki permeabilitas rendah untuk meminimalkan adanya infiltrasi ( $\mathrm{Li}$ et al., 2016). Beragam jenis material lapisan kedap air telah banyak dikembangkanantara lain adalah tanah lempung, geomembran, lapisan geosintetik, maupun gabungan dari material lain (Turan dan Ergun, 2009). Salah satu tanah lempung alami yang digunakan sebagai tanah dasar kedap air penahan lindi TPA adalah bentonit. Bentonit memiliki nilai permeabilitas yang rendah sehingga cocok digunakan sebagai lapisan penahan lindi. Walaupun bentonit memiliki nilai permeabilitas yang rendah, stabilitasgesernya tidak begitu kuat sehingga berpotensi mengalami keruntuhan apabila dipasang di daerah lereng.

Disisi lain, proses pembangunan konstruksi juga menyisakan permasalahan terkait dengan penanganan limbah yang dihasilkan dari aktivitas pembangunan dan pembongkaran bangunan. Limbah bangunan ini sebagian besar berupa batu bata, campuran pasir dan semen, serta beton, yang biasanya hanya ditimbun di suatu tempat atau digunakan sebagai urugan lahan. Pemanfaatan limbah bangunan sebagai bahan tambahan pernah diteliti oleh beberapa peneliti seperti Melbouci (2009), dimanapenambahan persentasetententu dari limbah bangunan pada tanah menunjukkan peningkatan kekuatan geser tanah.

Upaya peningkatanstabilitas tanah dasar kedap air penahan lindi TPA adalah melalui penambahan material lain yang memilikikuat geser yang tinggi. Material yang memiliki karakteristik semacam ini salah satunya adalah limbah konstruksi. Namun, penelitian mengenai pengaruh penambahanlimbah bangunan terhadap kekuatan geser tanah bentonit belum tersedia,sehingga dibutuhkan suatu pengujian untuk mengetahui pengaruh penambahan limbah konstruksi terhadap kuat geser campuran bentonit dan pengaruhnya terhadap nilai permeabilitas bahan campuran tersebut.

\section{Metodologi Penelitian}

Bahan utama yang digunakan dalam penelitian ini adalah tanah lempung jenis bentonit yang diperoleh dari Jawa Timur.Bentonit yang digunakan berwarna putih keabu-abuan dan berbentuk bubuk halus seperti dapat dilihat dari Gambar 1.
Bentonit adalah tanah liat yang reaktif dengan kandungan utama smectite, kuarsa, dan kaolin(Karnland 2010). Karakteristik fisik dan kimia dari lempung bentonit memainkan peran penting dalam perilaku mekanisnya,dengan sifat-sifat yang dirangkum pada

Tabel 1.

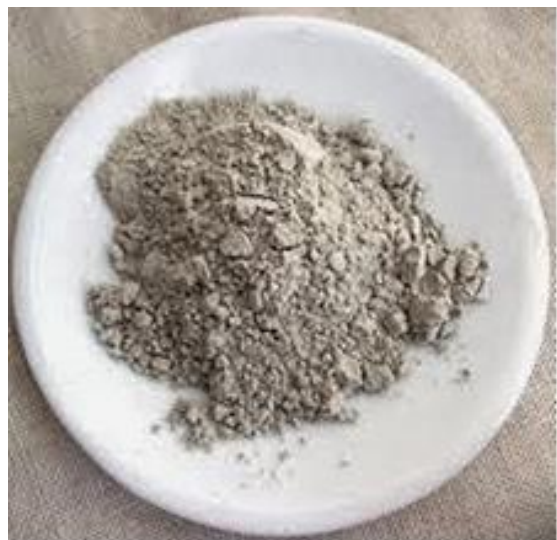

Gambar 1. Sampel bentonite

Bahan campuran tambahan dalam penelitian ini adalah limbah bangunan yang merupakan hasil bongkaran dinding (tembok) bangunan yang terdiri dari campuran semen pasir dan batu bata yang diperoleh dari bongkaran dinding bangunan di daerah Semarang, termasuk puing-puing, pecahan batu, dan beton dari proyek-proyek perumahan.

Tabel 1. Properti lempung bentonit

\begin{tabular}{ll}
\hline Komponen & Nilai \\
\hline Rumus & Al2O3•4SiO2H2O \\
Kimia & Putih keabuan \\
Warna & 2,75 \\
Sampel C & $7-9$ \\
$\mathrm{pH}$ & $43 \%$ \\
Kadar air & \\
\hline
\end{tabular}

Tekstur, bentuk fisik, dan warna butiran limbah bangunan sangat bervariasi karena adanya variasi dalam distribusi unsur penyusun limbah bangunan seperti yang ditunjukkan pada Gambar 2. Butiran pasir yang telah tercampur mortar dan batu bata dari limbah pembongkaran bangunan digunakan sebagai material tambahan stabilisasi dalam penelitian ini. Ukuran butiran limbah bangunan adalah antara 2,36 - 4,75 $\mathrm{mm}$.

Serangkaian uji laboratorium untuk mengetahui kontribusi limbah bangunan pada perilaku stabilitas geser lempung bentonite 
dilakukan dengan menggunakan uji geser langsung sesuai dengan ASTM D3080.Persentase penambahan limbah bangunan yang berbeda digunakan untuk menyelidiki pengaruh penambahan limbah bangunan terhadap kuat geser tanah lempung bentonit.

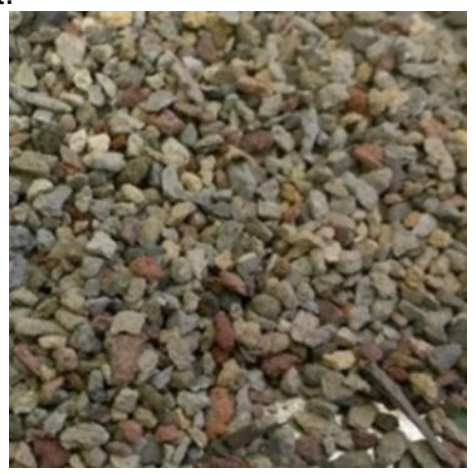

Gambar 2. Sampel limbah bangunan

Variasi penambahan limbah bangunan (LK) yang diuji adalah sebanyak 5\%, 10\%, dan $15 \%$ seperti yang disajikan padaTabel 2 . Sampel uji dipersiapkan dan ditimbang dalam kondisi kering sebelum dicampur sesuai variasi yang sudah ditentukan. Pengeringan dilakukan dengan memasukkan semua bahan ke dalam oven bersuhu $105^{\circ} \mathrm{C}$ selama 24 jam.

Tabel 2. Variasi penambahan limbah bangunan

\begin{tabular}{ll}
\hline Sampel & Komposisi \\
\hline B0 & Bentonit + 0\% LK \\
B5 & Bentonit + 5\% LK \\
B10 & Bentonit + 10\% LK \\
B15 & Bentonit + 15\% LK \\
\hline
\end{tabular}

Pencampuran dalam konsisi kering ini bertujuan untuk mendapatkan campuran yang homogen, mengingat bentonit akan cenderung menggumpal dan menyulitkan proses pencampuran apabila pencampuran dilakukan dalam kondisi basah.Sebelum pelaksanaan uji geser langsung, dilakukan uji kepadatan standar (standard proctor test) sesuai dengan ASTM D698. Uji kepadatan standar dilakukan juga untuk menentukan kadar air optimum sampel. Hasil uji kepadatan standar disajikan pada Tabel 3.

Tabel 3. Uji kepadatan standar

\begin{tabular}{ll}
\hline Parameter & Nilai \\
\hline MDD & $1,07 \mathrm{gr} / \mathrm{cm}^{3}$ \\
OMC & $42 \%$ \\
\hline
\end{tabular}

Hasil uji kepadatan standar menunjukkan bahwa kadar air optimum dari sampel adalah sebesar $42 \%$ dengan MDD sebesar 1,07 gr/cm3. Setelah proses pencampuran semua material dalam kondisi kering, dilakukan penambahan air hingga kadar air tiap sampel mencapai $42 \%$. Semua sampel kemudian disimpan selama 24 jam sebelum dilakukan pengujian geser langsung.

Kekuatan geser tanah dievaluasi melalui beberapa parameter diantaranya kohesi tanah $(c)$, sudut gesekan internal $(\phi)$ dan tegangan geser(т). Sesuai dengan ASTM D3080, uji geser langsung dilakukan pada tiga tegangan normal yang berbeda untuk masing-masing sampel. Dalam penelitian ini, spesimen yang dibuat dari material bentonit dan limbahbangunandiberikan tegangan normal sebesar $50 \mathrm{kPa}, 100 \mathrm{kPa}$ dan $200 \mathrm{kPa}$.

Setelah dilakukan uji geser, semua sampel diuji kemampuan permeabilitasnya dengan menggunakan uji permeabilitas atau hydraulic conductivity test. Pelaksanaan uji permeabiltas dilakukan dengan mengikuti panduan dari ASTM (2001a). Hasil dari uji permeabilitas kemudian dianalisa dan dibahas untuk mengetahui pengaruh penambahan material limbah bangunan terhadap permeabilitas bahan.

\section{Hasil dan Pembahasan}

\section{Uji Geser Langsung}

Pengujian uji geser langsung bertujuan untuk menentukan parameter kuat geser tanah kohesi (c) dan sudut geser tanah ( $\varnothing$ ). Pengujian geser langsung dilakukan padabentonit dengan penambahan limbah bangunan sebesar $0 \%, 5 \%, 10 \%$, dan $15 \%$. Grafik hubungan antara tegangan normal dan tegangan geser dipakai untuk menentukan C dan Øyang dapat dilihat pada Gambar 3.

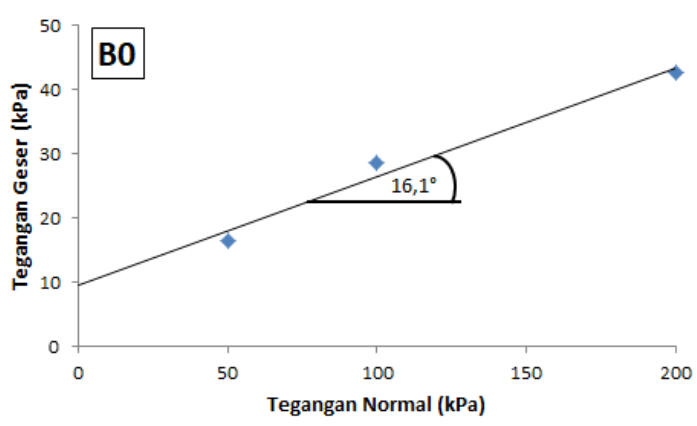

Gambar 3. Tegangan Normal dan Tegangan Geser Bentonit Murni

Berdasarkan grafik padaGambar 3,dapat dilihat bahwa pada tegangan normal $50 \mathrm{kPa}$, $100 \mathrm{kPa}$, dan $200 \mathrm{kPa}$ diperoleh nilai tegangan geser secara berturut-turut adalah 
sebesar 16,49 kPa; 28,50 kPa; dan42,52 $\mathrm{kPa}$. Dari hasil tersebut didapatkan nilai sudut geser $(\varnothing)$ sebesar $16,1^{\circ}$

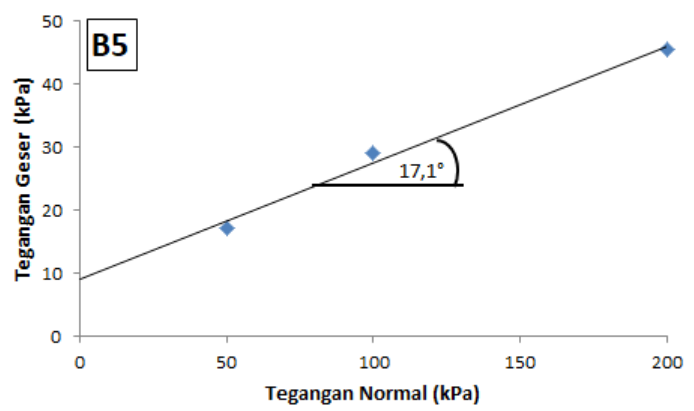

Gambar 4. Tegangan Normal dan Tegangan Geser Bentonit + Limbah Bangunan5\%

Berdasarkan grafik pada Gambar 4, dapat dilihat bahwapada tegangan normal sebesar50 kPa, $100 \mathrm{kPa}$, dan $200 \mathrm{kPa}$ diperoleh nilai tegangan geser secara berturut-turut adalah sebesar17,30 $\mathrm{kPa}$; 29,06 kPa; dan 45,57 kPa. Dari hasil tersebut didapatkan nilai sudut geser (Ø) sebesar $17,1^{\circ}$

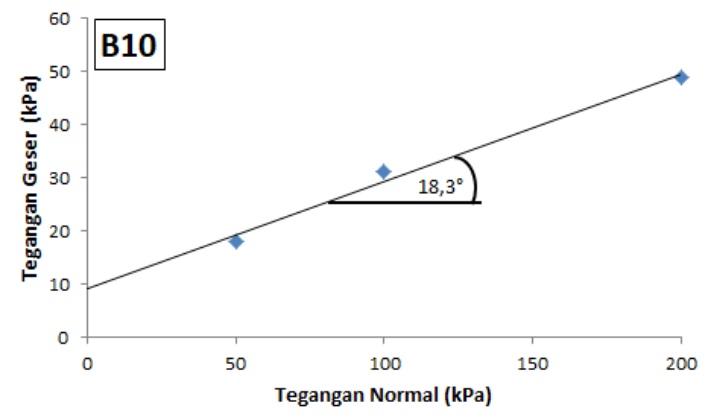

Gambar 5. Tegangan Normal dan Tegangan Geser Bentonit + Limbah Bangunan 10\%
Berdasarkan grafik pada Gambar 5, dapat dilihat bahwa pada tegangan normal sebesar $50 \mathrm{kPa}, 100 \mathrm{kPa}$, dan $200 \mathrm{kPa}$ diperoleh nilai tegangan geser secara berturut-turut adalah sebesar18,02 kPa; 31,32 $\mathrm{kPa}$; dan48,92 $\mathrm{kPa}$. Dari hasil tersebut didapatkan nilai sudut geser $(\varnothing)$ sebesar18,3․

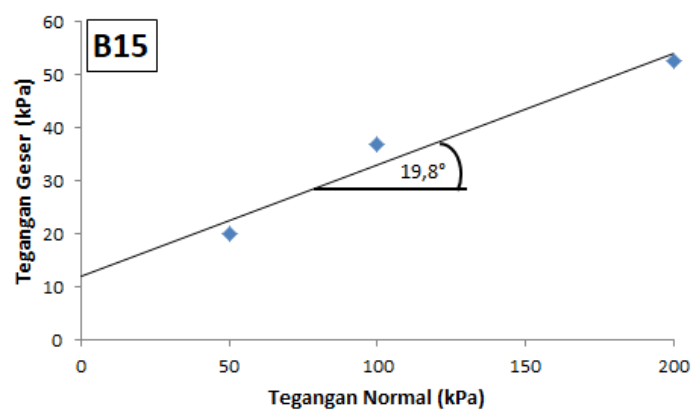

Gambar 6. Tegangan Normal dan Tegangan Geser Bentonit + Limbah Bangunan 15\%

Berdasarkan grafik pada Gambar 6,dapat dilihat bahwa pada tegangan normal $50 \mathrm{kPa}$, $100 \mathrm{kPa}$, dan $200 \mathrm{kPa}$ diperoleh nilai tegangan geser secara berturut-turut adalah sebesar19,97kPa; 36,91 kPa; dan $52,78 \mathrm{kPa}$. Dari hasil tersebut didapatkan nilai sudut geser $(\varnothing)$ sebesar $19,8^{\circ}$.

Keempat grafik di atas menampilkan hasil tegangan geser dari bentonit dan tiga campuran bentonit dengan limbah bangunan masing-masing sebesar $5 \%, 10 \%$, dan $15 \%$. Pada tegangan normal $50 \mathrm{kPa}, 100 \mathrm{kPa}$, dan $200 \mathrm{kPa}$, diperoleh tegangan geser yang semakin meningkat seiring dengan adanya penambahan limbah bangunan.

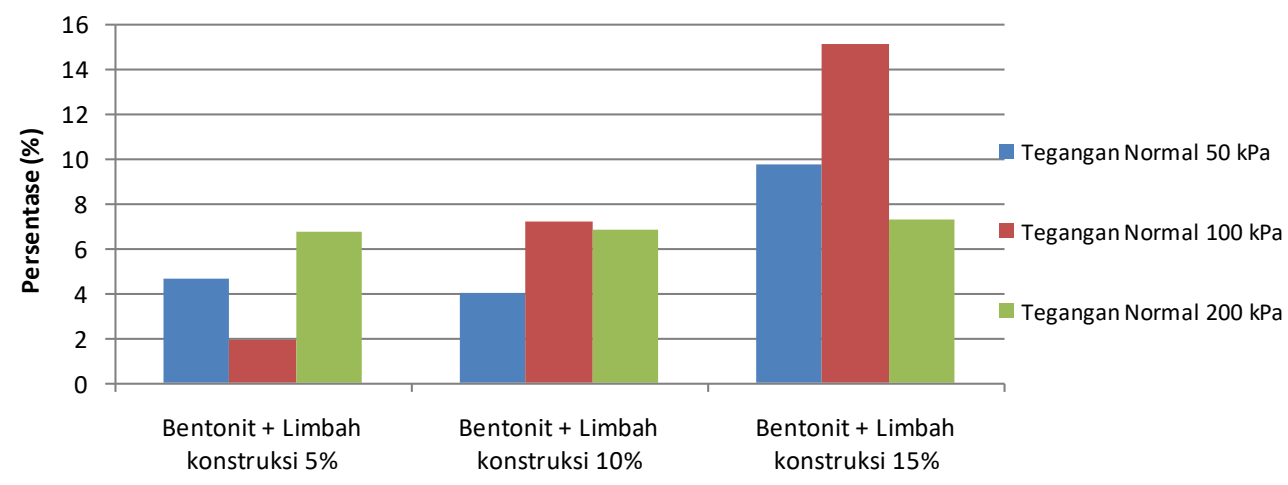

Gambar 7. Persentase Kenaikan Tegangan Geser

Berdasarkan Gambar 7,pada tegangan normal $50 \mathrm{kPa}$, kenaikan tegangan geser memliki persentasesebesar 4,68\%; 4\%; dan
9,78\%. Kemudian pada tegangan normal 100 $\mathrm{kPa}$, tegangan geser meningkat dengan persentase sebesar $1,92 \% ; 7,2 \%$; dan 
$15,13 \%$. Sedangkan pada tegangan normal $200 \mathrm{kPa}$, persentase peningkatan tegangan geser yaitu sebesar 6,7\%; 6,85\%; dan 7,3\%. Peningkatan tegangan geser tertinggi ada pada tegangan normal $100 \mathrm{kPa}$ dengan persentase hingga 15\% danterus mengalami peningkatan seiring dengan adanya penambahan limbah bangunan. Semakin besar nilai kuat geser, maka kemungkinan terjadinya pergeseran tanah akan semakin kecil (Falamaki dkk, 2015).

Menurut Melbouci (2009), penambahan limbah bangunanpadacampuran akan meningkatkan nilai kuat geser. Berdasarkan penelitian tersebut, dilakukan penambahan limbah bangunan dengan variasi sebesar $5 \%$, $10 \%$, $15 \%$, dan $20 \%$ dimanakuat geser yang awalnya bernilai sebesar $0,128 \mathrm{~kg} / \mathrm{cm}^{2}$ meningkat hingga menjadi $0,546 \mathrm{~kg} / \mathrm{cm}^{2}$. Hal tersebut sesuai dengan hasil penelitian ini di mana penambahan limbah bangunan meningkatkan nilai kuat geser.

\section{Uji Permeabilitas}

Pengujian permeabilitas dilakukan dengan menggunakan metode falling head. Metode tes ini meliputi prosedur untuk mendapatkan nilai koefisien K,yaitu nilai-nilai yang menyatakan kemudahan aliran air untuk lolos melalui pembatas / tanah. Pengujian permeabilitas dilakukan padabentonit yang dicampur dengan limbah bangunan $0 \%, 5 \%$, $10 \%$, dan $15 \%$. Hasil pengujian permeabilitas dapat dilihat pada Tabel 4berikut ini

Tabel 4. Nilai Koefisien Permeabilitas

\begin{tabular}{llc}
\hline No. & Sampel & $\begin{array}{c}\text { Koefisien } \\
\text { Permeabilitas (k) } \\
\text { (cm/s) }\end{array}$ \\
\hline 1 & B0 & $1,27 \mathrm{E}-11$ \\
2 & B5 & $2,13 \mathrm{E}-11$ \\
3 & B10 & $6,82 \mathrm{E}-11$ \\
4 & B15 & $1,51 \mathrm{E}-10$ \\
\hline
\end{tabular}

Berdasarkan hasil pengujian padaTabel 4,dapat ditarik hubungan antara pengaruh penambahan limbah bangunan terhadap nilai koefisien permeabilitas yang disajikan pada Gambar 8.

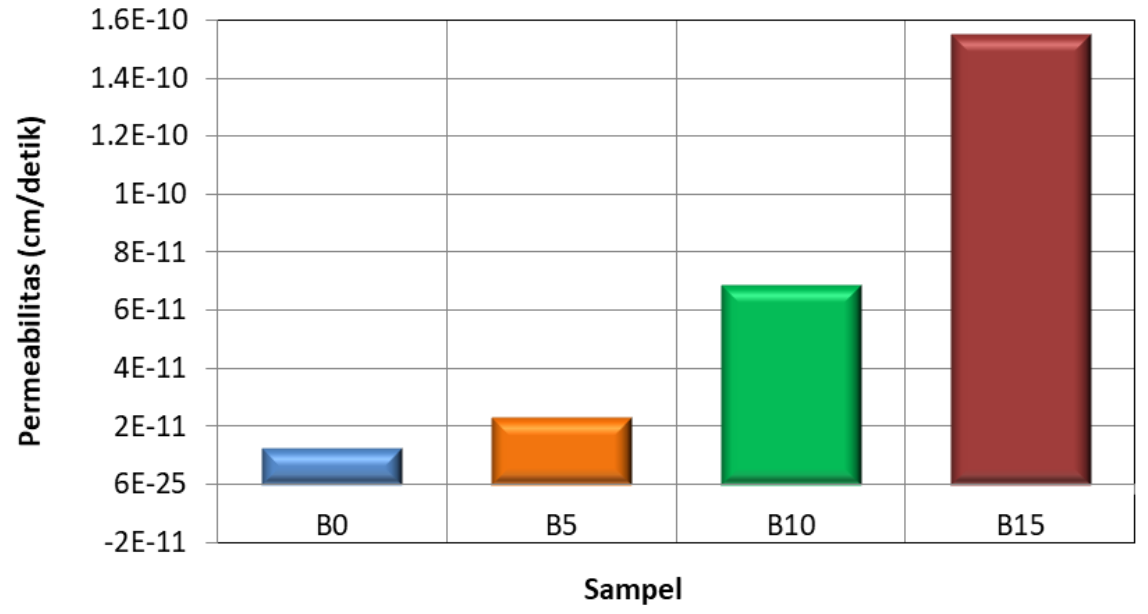

Gambar 8. Grafik Hasil Pengujian Permeabilitas

Berdasarkan Gambar 8,dapat ditarik kesimpulan bahwa dengan semakin meningkatnya campuran limbah bangunan sebesar $0 \%, 5 \%, 10 \%$, dan $15 \%$, maka diperoleh nilai koefisien permeabilitas yang semakin besar, namun peningkatan yang terjadi tidak terlalu signifikan. Nilai koefisien

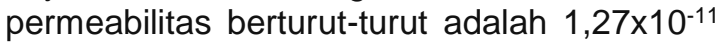
$\mathrm{cm} / \mathrm{s} ; 2,13 \times 10^{-11} \mathrm{~cm} / \mathrm{s} ; 6,82 \times 10^{-11} \mathrm{~cm} / \mathrm{s}$; dan $1,51 \times 10^{-11} \mathrm{~cm} / \mathrm{s}$. Hal ini menandakan bahwa nilai koefisien permeabilitas bergantung pada ukuran butiran tanah, dimana semakin rendah ukuran butiran maka semakin rendah pula kemampuannya untuk meloloskan air. Nilai permeabilitas yang diperbolehkan untuk lapisan liner landfill adalah kurang dari $10^{-7}$ cm/det (Daniel dan Benson, 1990; Osinubi, Eberemu dan Amadi, 2009; Amadi dan Eberemu, 2012), sedangkan Environmental Protection Agency (EPA) (2000) menyebutkan bahwa lapisan dasar landfill harus kurang dari atau sama dengan $10^{-7} \mathrm{~cm} /$ det. Keempat sampel memiliki koefisien permeabilitas dalam kisaran 10-11 cm/det, maka seluruhsampel memenuhi kriteria dari referensi di atas untuk dapat digunakan sebagai lapisan dasar TPA.

\section{Kesimpulan}

Kekuatan geser tanah liat bentonit yang digunakan sebagai lapisan penahan lindi TPA 
dapat ditingkatkan dengan penambahan limbah bangunanyang memiliki kuat geser tinggi.Pada penambahan limbah bangunansebesar $0 \%, 5 \%, 10 \%$, dan $15 \%$ pada tegangan normal $50 \mathrm{kPa}$, diperoleh tegangan geser yang semakin meningkat seiring dengan adanya penambahan limbah bangunan. Peningkatan tegangan geser juga terjadi pada tegangan normal $100 \mathrm{kPa}$ dan $200 \mathrm{kPa}$ seiring dengan penambahan persentase limbah bangunan. Peningkatan konsentrasi limbah bangunan juga menyebabkan meningkatnya nilai koefisien permeabilitas, namun tidak secara signifikan. Nilai koefisien permeabilitas akibat penambahan limbah bangunansebesar $0 \%$, $5 \%$, $10 \%$, dan $15 \%$ adalah berturut-turut sebesar $1,27 \times 10^{-11} \mathrm{~cm} / \mathrm{s} ; 2,13 \times 10^{-11} \mathrm{~cm} / \mathrm{s}$; $6,82 \times 10^{-11} \mathrm{~cm} / \mathrm{s} ; \quad$ dan $1,51 \times 10^{-11} \mathrm{~cm} / \mathrm{s}$. Penambahan limbah bangunan campuran masih memenuhi nilai permeabilitas lapisan landfill berdasarkan EPA, yaitu kurang dari atau sama dengan $10^{-7}$.

\section{Daftar Pustaka}

Amadi, Agapitus Ahamefule, dan Adrian Oshioname Eberemu. (2012). Delineation of compaction criteria for acceptable hydraulic conductivity of lateritic soil-bentonite mixtures designed as landfill liners. Environmental Earth Sciences.

ASTM D3080 / D3080M-11. (2011). Standard Test Method for Direct Shear Test of Soils Under Consolidated Drained Conditions. ASTM International

ASTM D698-12e2, Standard Test Methods for Laboratory Compaction Characteristics of Soil Using Standard Effort (12 $400 \mathrm{ft}$ $\mathrm{lbf} / \mathrm{tt} 3 \quad(600 \quad \mathrm{kN}-\mathrm{m} / \mathrm{m3})), \quad$ ASTM International.

Daniel, David E., dan Craig H. Benson. (1990). Water Content-Density Criteria for Compacted Soil Liners.Journal of Geotechnical Engineering.

Environmental Protection Agency. (2000). Landfill Manuals-Landfill Site Design.Environmental Protection Agency Ireland.

Falamaki, A., Eskandari, M., Homaee, M. and Gerashi, M.(2018).An Improved
Multilayer Compacted Clay Liner by Adding Bentonite and Phosphate Compound to Sandy Soil.KSCE Journal of Civil Engineering.

He, J., Wang, Y., Li, Y. and Ruan, X.C.(2015). Effects of leachate infiltration and desiccation cracks on hydraulic conductivity of compacted clay.Water Science and Engineering.

Karnland, O. (2010). Chemical and mineralogical characterization of the bentonite procedure in a KBS-3 repository.SKB Technical Report.

Li, J.H., Li, L., Chen, R. and Li, D.Q. (2016). Cracking and vertical preferential flow through landfill clay liners. Engineering Geology.

Manaf, L. A., Samah, M. A. A. dan Zukki, N. I. M. (2005). Municipal solid waste management in Nepal: Practices and challenges. Elsevier Ltd, 25(5), hal. 555562.

Melbouci, B., (2009). Compaction and shearing behaviour study of recycled aggregates. Construction and Building Materials, 23(8), hal. 2723-2730.

Osinubi, K. J., et al. (2009). Compacted lateritic soil treated with blast furnace slag as hydraulic barriers in waste containment systems. International Journal of Risk Assessment and Management.

Renou, S., Givaudan, J.G., Poulain, S., Dirassouyan, F. and Moulin, P.(2008). Landfill leachate treatment: Review and opportunity.Journal of Hazardous Materials.

Turan, N. G. dan Ergun, O. N. (2009). Removal of $\mathrm{Cu}$ (II) from leachate using natural zeolite as a landfill liner material. Journal of Hazardous Materials.

Zhang, D. Q., Tan, S. K. dan Gersberg, R. M. (2010). Municipal solid waste management in China: Status, problems and challenges. Journal of Environmental Management. 